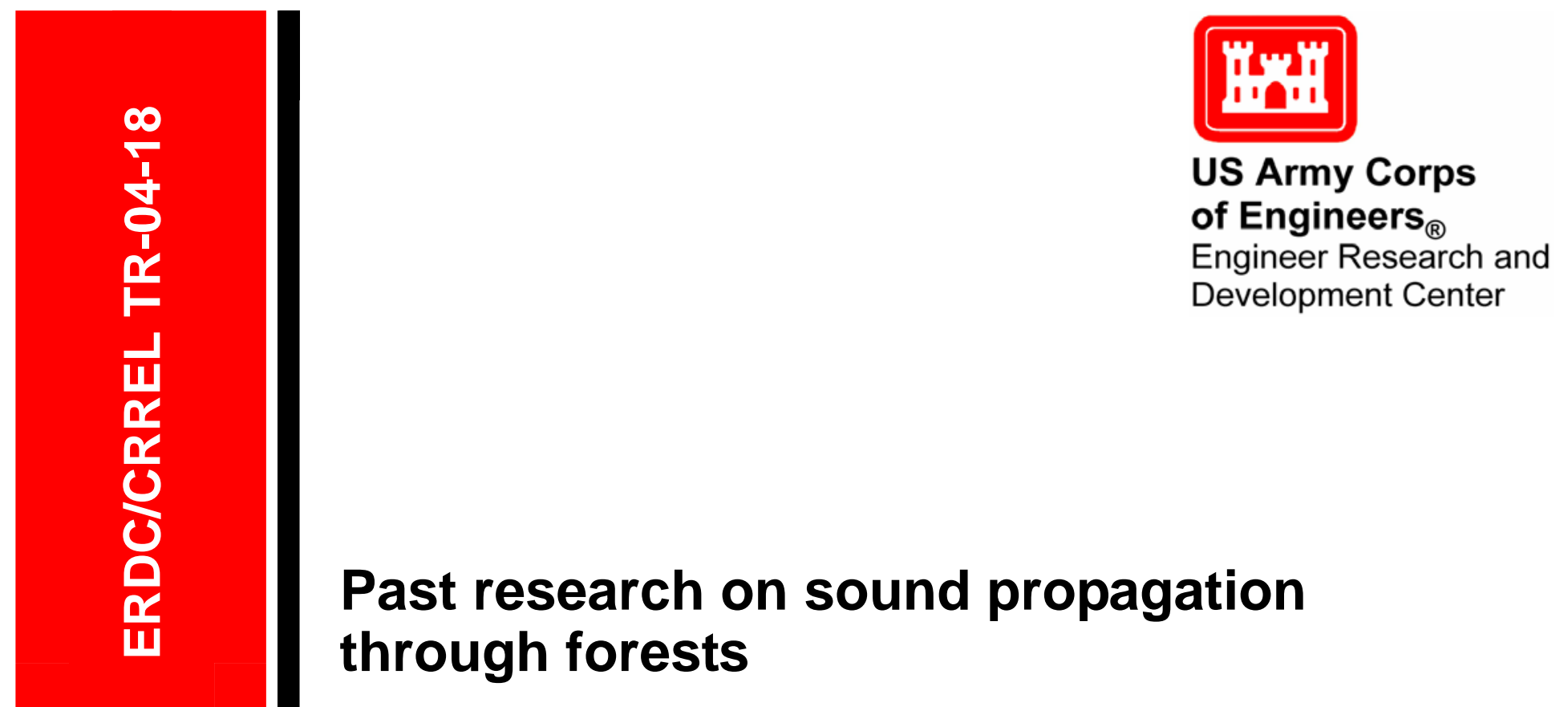

Donald G. Albert

October 2004

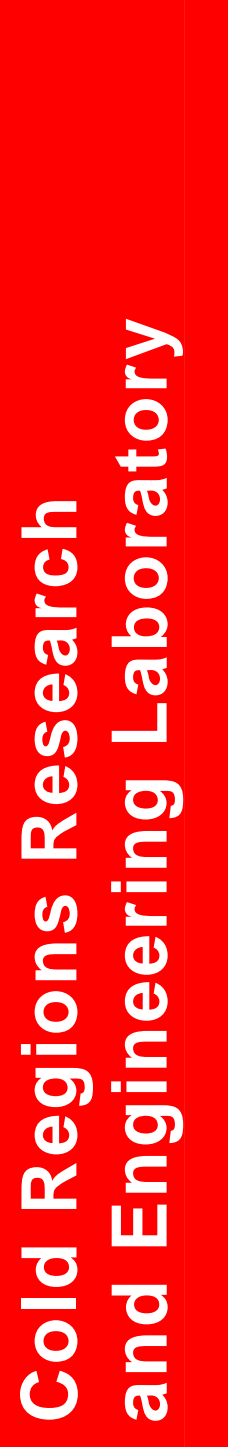

Approved for public release; distribution is unlimited. 



\section{Past research on sound propagation through forests}

Donald G. Albert

${ }^{*}$ Cold Regions Research and Engineering Laboratory

U.S. Army Engineer Research and Development Center

72 Lyme Road

Hanover, New Hampshire 03755

Approved for public release; distribution is unlimited 


\section{ABSTRACT}

This report reviews past scientific research to determine whether forests have any noise reduction effects for blast noise from artillery training or explosions. Unfortunately, there has been very little relevant work that would contribute to answering this question. For military noise sources, the main frequencies of interest are below $100 \mathrm{~Hz}$. Most of the past investigations have been done at high frequencies using low-amplitude continuous wave noise sources rather than high-amplitude impulsive sources. For these reasons, additional measurements will be needed to determine the effect of forests on artillery and blast noise.

DISCLAIMER: The contents of this report are not to be used for advertising, publication, or promotional purposes. Citation of trade names does not constitute an official endorsement or approval of the use of such commercial products. All product names and trademarks cited are the property of their respective owners. The findings of this report are not to be construed as an official Department of the Army position unless so designated by other authorized documents. 


\section{CONTENTS}

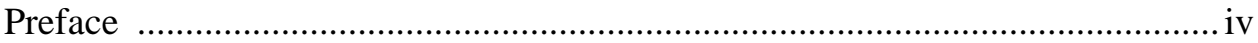

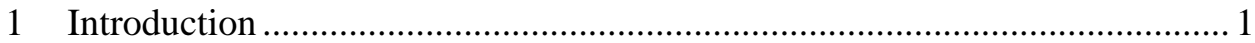

2 Sound propagation in forests — early work (before 1970) .............................. 2

3 Sound propagation in forests_ — current understanding ................................... 3

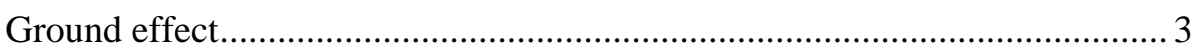

Relationship between ground parameters and acoustic parameters ............... 4

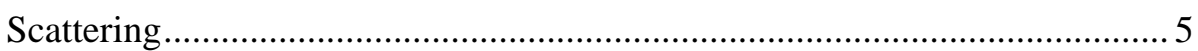

Absorption from vegetation................................................................... 7

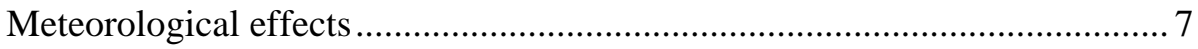

Additional references not discussed in detail ................................................. 8

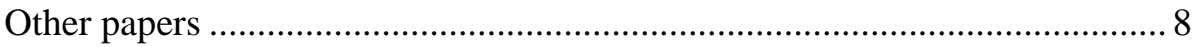

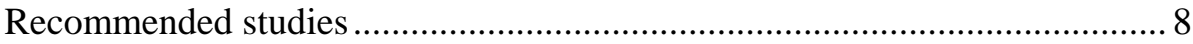

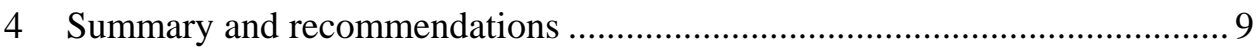

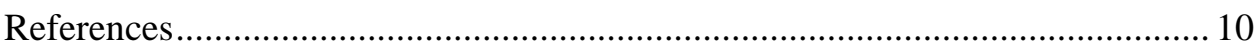

Appendix A: Recent work ....................................................................... 16

\section{ILLUSTRATIONS}

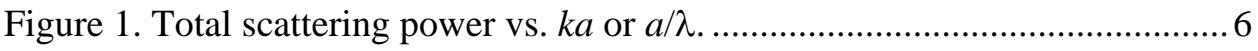

Figure 2. Measured and predicted acoustic attenuation in a forest for a short

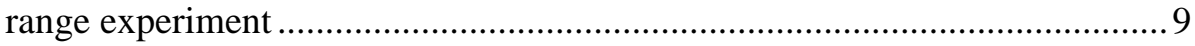

\section{TABLES}

Table 1. Scattered power as a function of acoustic wave frequency. .................... 7 


\section{PREFACE}

This report was prepared by Dr. Donald G. Albert, Research Geophysicist, Geophysical Sciences Branch, U.S. Army Engineer Research and Development Center, Cold Regions Research and Engineering Laboratory.

In recent years the increase of civilian populations living on the outskirts of U.S. Army installations has led to more frequent noise complaints. While the Army normally uses forest management techniques to ensure the health of the forests on its installations, a question that has arisen is whether these forest practices, including tree harvesting, might adversely impact the noise problem by reducing the noise absorption characteristics of the forested land. Underlying this question is the assumption that forests absorb noise. While this is certainly true at high frequencies (in the $\mathrm{kHz}$ region), little work has been done at the lower frequencies (below $100 \mathrm{~Hz}$ ) often produced by Army demolition and training activities. As a result of this lack of knowledge, ERDC, under the direction of Dr. Larry Pater, ERDC-CERL, is embarking on a study of the low frequency noise attenuation by forests. As part of this study, previous work on the acoustic effect of forests was reviewed, and this report presents the results of that study. Since this study revealed that research is still needed to understand the forest effect, further experimental measurements and theoretical work on this problem are planned.

The author thanks Tom Vorac, US Army Environmental Center, and Dr. Larry Pater, ERDC-CERL, Project Leader for Military Noise Management, for funding this research. Dr. Michael White and Dr. Michelle Swearingen provided helpful reviews.

This report was prepared under the general supervision of Dr. Richard Detsch, Chief, Geophysical Sciences Branch; and James Wuebben, Acting Director, CRREL.

The Commander of the Engineer Research and Development Center is COL James R. Rowan, EN. The Director is Dr. James R. Houston. 


\title{
Past Research on Sound Propagation Through Forests
}

\author{
DONALD G. ALBERT
}

\section{INTRODUCTION}

Past studies of acoustic propagation in forests were done primarily for two applications: 1) reduction of traffic noise, and 2) biological studies, especially bird and other animal communication. Because of these applications, most studies used continuous wave (CW) sources (usually, a loudspeaker emitting tones or sweeps) and the measurements were conducted over relatively short ranges, usually from a few meters to a few tens of meters. The short propagation distances, low amplitude levels, and use of non-impulsive sources all limit the applicability of these studies to blast noise effects.

Noise produced by artillery training is primarily low frequency, high amplitude impulse noise. It is similar in many ways to blast noise produced by explosive charges. A peak frequency of around $30 \mathrm{~Hz}$ is typical, with a peak acoustic wavelength of about $10 \mathrm{~m}$. This frequency and wavelength range differs markedly from traffic and most animal acoustic noise. These applications typically concern a frequency range of $1-10 \mathrm{kHz}$, with wavelengths of 3-30 cm.

There are a number of factors affecting outdoor sound propagation (Sutherland and Daigle 1997) that will be briefly listed here. The distance between the source and receiver determines the amount of loss from wavefront spreading (or divergence), which decreases the peak sound pressure as $1 / R$, where $R$ is the propagation distance. Attenuation by air absorption increases with distance, and is a larger effect at higher frequencies. The ground has two different effects, the interference between the direct and reflected sound and the effect of ground impedance. Reflections from the ground surface interferes with the direct sound path in a way that varies, depending on the geometry, frequency, and ground impedance. Acoustical ground impedance itself also varies according to the nature of the ground surface. Highly porous surfaces, such as might be present in a forest, will have higher sound energy loss because more incident sound energy will enter the pores and be dissipated by viscous and thermal losses. Meteorological 
conditions can have a large influence, especially at longer distances. These include wind and temperature gradients that can bend sound propagation towards or away from the ground surface, enhancing propagation along the surface in downward refracting directions. Thus, meteorological conditions may cause an asymmetry in the areal distribution of sound levels, and also a time variability as atmospheric conditions change. Turbulent scattering tends to affect higher frequencies more than lower frequencies, and introduces an instantaneous fluctuation in the received sound levels. It also tends to blur or fill in the sharp shadow zones that would be otherwise be expected from interference or meteorology. Finally, obstructions along the propagation path, such as topography or sound barriers, can influence the sound levels by scattering, absorption, and diffraction. (See also Embleton 1996, Piercy et al. 1977.)

A forest can potentially reduce artillery noise over open ground in a number of ways: 1) differences in ground impedance produced by tree roots and decaying leaves or needles, 2) scattering and absorption from leaves, branches, and tree trunks, and 3) modification of meteorological conditions below the canopy. Past work is now examined to determine what is currently known about these factors. Previous literature reviews are available and have been consulted (Ringheim 1986, Swearingen et al. 1998). In addition, a review of biologically oriented work produced by one group from the Netherlands is worth consulting (Martens and Huisman 1986).

\section{SOUND PROPAGATION IN FORESTS-EARLY WORK (BEFORE 1970)}

Early measurements of the effect of forests or vegetation on sound propagation are difficult to compare, because the methods used, geometries, frequencies, and even definitions (such as for various absorption coefficients) varied from one paper to another. The locations of the sources and receivers could be within or outside the forest, adding another complicating factor. The mechanisms affecting propagation in this environment were not well understood.

Eyring (1946) was one of the first to publish experimental measurements of sound propagation through heavy vegetation. This paper is still the primary source for sound propagation in a jungle, but is limited somewhat by the technology available at the time. Coefficients of absorption by vegetation and by relative humidity (air absorption) were presented. However, the work was done in the jungle during the rainy season with wet, muddy ground present, a serious limitation in estimating the ground effect believed to be important to artillery noise mitigation. Other papers from the early years are given in the reference list. 


\section{SOUND PROPAGATION IN FORESTS-CURRENT UNDERSTANDING}

By the 1980s, the basic phenomena of sound propagation within forests at audible frequencies were understood. The main effects are the ground effect, scattering from tree trunks and branches, and absorption by leafy vegetation.

\section{Ground effect}

The ground effect causes increased attenuation at lower frequencies $(<500$ $800 \mathrm{~Hz}$ ) and has two components, interference and impedance. The interference between direct and reflected waves depends on the geometry $(R, h s, h r)$ and ground impedance. For most measurement situations, at short ranges and with sources and receivers within a few meters of the surface, a "ground effect dip" will exist for a particular narrow frequency band. This is the frequency band where the direct and reflected wave (including the phase shift caused by the impedance of the ground) add destructively, and it usually occurs somewhere within the $500 \mathrm{~Hz}-2 \mathrm{kHz}$ band. This peak in attenuation is narrow and tends to be lessened by meteorologically caused fluctuations.

In addition, the ground impedance will also cause attenuation for longer distances along the surface (Rudnick 1947, Ingard 1951, Chien and Soroka 1975, Donato 1976). Early papers recognizing the ground effect include Wiener and Keast (1959), Pao and Evans (1971), and Aylor (1972a). While Aylor (1972a) presented an approximate formula for the impedance effect of the ground, subsequent measurements (Albert and Orcutt 1990) did not agree with his equation, and instead show a trend of

$$
P \sim R^{-\mathrm{b}}
$$

where $R$ is the distance of propagation and $b$ is an attenuation coefficient that varies with the properties of the ground. For grass, they found $b=1.2$, while for snow-covered ground, $b=1.7$.

Theory predicts that the ground attenuation approaches zero as frequency approaches zero, and this tendency is confirmed by most measurements. But linear theory does not include high-amplitude, non-linear effects (Umnova et al. 2001), which may extend the ground absorption to lower frequencies. 


\section{Relationship between ground parameters and acoustic parameters}

The use of physically measured ground properties to predict or correlate with acoustic propagation parameters would seem to be a straightforward one, but this subject is actually one of considerable controversy. The main discrepancy is that direct measurements of soil flow resistivity (the resistance of the soil to gas flow) differ markedly from the values estimated from acoustic measurements. Because of this discrepancy, acousticians speak of effective flow resistivity when discussing acoustically determined values (Embleton et al. 1983). While some of this difference is ascribable to experimental error in the direct measurements (from soil sample disturbance and uncertainty over the proper soil thickness to use), error cannot account for all of the differences, which are typically a factor of 5 or 10 apart. Another reason is the dependence of the acoustic propagation on other parameters, including porosity, tortuosity, and pore size distribution, but again, even the best theories including these factors do not seem to agree with measured outdoor sound propagation data. Thus, attempts (Martens et al. 1985a) to correlate acoustic measurements with laboratory measurements of soil properties have not been successful to date.

Attenborough (1992) has discussed many of the ground impedance models used and gives different definitions of the effective ground impedance, depending upon the model used. Allard (1993) has shown how to resolve these differences to determine the true flow resistivity by explicitly including all of the nondimensional factors, such as the porosity and shape factors, in the definition of effective flow resistivity.

There is also some controversy over the effect of the top soil layers in a forest on acoustic propagation. Thus, Aylor (1972a) reported that needles on the ground caused no acoustic attenuation, and others (Heijden et al. 1983, Martens et al. 1985a) have reported no change in acoustic properties when the upper layers of vegetation and soil were removed. These results are incorrect, and could perhaps be caused by not removing enough of the areal extent of the detritus to affect the measurements. However, the references do not provide enough geometric information to evaluate this supposition.

Other researchers (Talaske 1980, Don and Cramond 1985) have found large changes in acoustic impedance when upper soil layers were removed or altered. In particular, Don and Cramond showed directly induced changes in the appearance of high frequency pulses and in the measured ground impedance as pine needles were added to the ground. All researchers agree that forest soils must be treated as layered (Talaske 1980, Don and Cramond 1985, Martens et al. 1985a), and that simple expressions for a homogeneous soil (without layers) do not agree with measured data. The layered nature of the soil implies that 


$$
Z_{\mathrm{c}}=Z_{\mathrm{s}} \tanh (k d)
$$

where

$$
\begin{aligned}
Z_{\mathrm{c}} & =\text { characteristic impedance } \\
Z_{\mathrm{s}} & =\text { specific surface impedance } \\
k & =\text { wavenumber in the soil } \\
d & =\text { layer thickness (Heijden et al. 1983). }
\end{aligned}
$$

This equation implies that the real part of the impedance will be nearly constant, and the imaginary part will decrease as frequency increases, in agreement with measured data.

The effective flow resistivity $\sigma_{\mathrm{e}}$ for a forest floor is usually low, implying that acoustic propagation losses from the ground impedance will be higher in these areas than over grass covered ground. Typical values (Sutherland and Daigle, 1997) of $\sigma_{\mathrm{e}}$ for grassland range from $200-400 \mathrm{kPa} \mathrm{s} \mathrm{m}^{-2}$. For forest floors, values range from 20-80, with 50 being typical. Others have reported values of 50 (Heijden et al. 1983), 60-70 (Price et al. 1988), and one reported a value of 7.5 (Huisman and Attenborough 1991) (for a different ground impedance model). Others (Don and Cramond 1985, Martens et al. 1985a, Storeheier et al. 1995) have shown low impedance measurements, but did not determine effective flow resistivity values.

\section{Scattering}

Another recognized effect of forests on sound propagation is scattering from trunks and branches. The amount of scattering increases with increasing frequency, and becomes an important factor in acoustic propagation when the wavelength approaches the size of the scatterers. In an early reference to scattering in forests, Rayleigh (1945) mentions the phenomenon of harmonic echoes, where "echoes returned from such reflecting bodies as groups of trees may be raised an octave” (Rayleigh 1945, vol II, p. 296) because of the frequency dependence of the scattering.

Scattering from a single cylinder obeys the following equations for long and short wavelengths (Lindsay 1960, Morse and Ingard 1968)

$$
\begin{aligned}
& \text { Ws } \sim 6 \pi^{5} a^{4} \lambda^{-3} I_{0}=1836 a^{4} \lambda^{-3} I_{0}, k a<<1 \\
& \text { Ws } \sim 4 a I_{0}, k a>>1
\end{aligned}
$$


where

$$
\begin{aligned}
W s & =\text { total scattered power } \\
I_{0} & =\text { wave intensity } \\
a & =\text { scattering cylinder radius } \\
\lambda & =\text { acoustic wavelength } \\
k a & =2 \pi a / \lambda .
\end{aligned}
$$

The maximum scattered power is equivalent to the power in a beam that is twice the width of the scattering cylinder. In most situations, the scattered power will be very small with respect to the total power of the source $\left(=4 \pi r^{2} I_{0}\right)$. From these expressions and from a plot (Fig. 1) of scattering power vs. $k a$ (Lindsay 1960, Morse and Ingard 1968), Table 1 gives the scattered power as a function of frequency for various tree trunk or branch diameters. It is apparent from Table 1 that scattering even from a single large tree trunk (with a diameter of $1 \mathrm{~m}$ or more) will have a negligible effect on low frequency sound propagation.

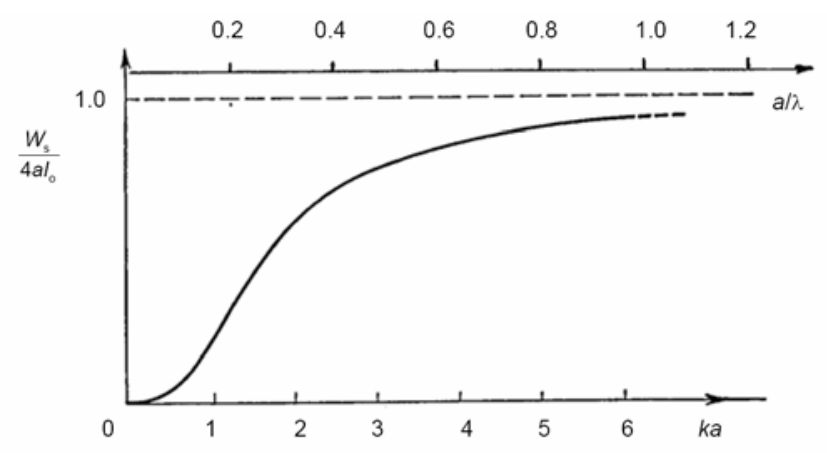

Figure 1. Total scattering power vs. ka or $a / \lambda$. Here, $a$ is the radius of the cylinder, $\lambda$ the acoustic wavelength, and $k$ the acoustic wavenumber. (After Lindsay 1960.)

Multiple scattering is expected within a forest, and theoretical and computational estimates of this effect compare well with measured data (Leschnik 1980, Bullen and Fricke 1982, Nannariello and Fricke 1999, Sakai et al. 1998, 2001). This effect will still remain relatively small and important only at high frequencies. For frequencies above $1 \mathrm{kHz}$, the effect of a band $d$ meters deep containing very large trees and thick foliage can be estimated from Bullen and Fricke (1982) 
Scattering Attenuation $(\mathrm{dB})=8.5+0.12 d$

Thus, a 100-m belt of this forest is predicted to cause $20 \mathrm{~dB}$ of attenuation from scattering in addition to the $40 \mathrm{~dB}$ caused by wavefront spreading.

Table 1. Scattered power as a function of acoustic wave frequency.

\begin{tabular}{|c|c|c|c|c|c|c|c|}
\hline & \multicolumn{6}{|c|}{ Radius of scattering cylinder, $a$} \\
\hline & & \multicolumn{2}{|c|}{$0.5 \mathrm{~m}$} & \multicolumn{2}{|c|}{$0.1 \mathrm{~m}$} & \multicolumn{2}{|c|}{$0.01 \mathrm{~m}$} \\
\hline$k a$ & $W s / 4$ a $I_{0}$ & $f(\mathrm{~Hz})$ & $\lambda(\mathrm{m})$ & $f(\mathrm{~Hz})$ & $\lambda(\mathrm{m})$ & $f(\mathrm{kHz})$ & $\lambda(\mathrm{mm})$ \\
\hline 0.1 & 0.0019 & 11 & 31 & 54 & 6.3 & 0.54 & 630 \\
\hline 0.3 & 0.05 & 33 & 10 & 162 & 2.1 & 1.6 & 210 \\
\hline 1 & 0.20 & 108 & 3.1 & 541 & 0.63 & 5.4 & 63 \\
\hline 2 & 0.57 & 217 & 1.6 & 1082 & 0.31 & 11 & 31 \\
\hline 3 & 0.76 & 325 & 1.0 & 1623 & 0.21 & 16 & 21 \\
\hline 5 & 0.89 & 541 & 0.63 & 2706 & 0.13 & 27 & 13 \\
\hline 10 & 1.00 & 1082 & 0.31 & 5411 & 0.063 & 54 & 6 \\
\hline
\end{tabular}

\section{Absorption from vegetation}

Absorption from leaves and foliage is only important at higher frequencies, in the mid to high kilohertz range and higher, and seems to be smaller than scattering losses. Direct, close-up measurements of this absorption have been conducted (Aylor 1972b, 1981; Martens 1980; Martens and Michelsen 1981; Martens et al. 1982, 1985b; Tang et al. 1986; Watanabe and Yamada 1996), along with measurements of absorption from tree bark (Reethof et al. 1976). However, most propagation theories ignore this effect, and it is relatively unimportant for artillery and training noise.

\section{Meteorological effects}

Vertical temperature or wind gradients cause sound rays to bend (or refract) upward or downward, affecting the received sound pressure level. However, meteorological conditions are rarely discussed in forest propagation studies. In part the omission may be because of the short propagation ranges used, and much past experimental work was stopped when wind speeds picked up, etc. Meteorological conditions won't matter at all until at least $200 \mathrm{~m}$ propagation distance and longer. While no temperature gradients were detected under a thick jungle canopy (Eyring 1946), Huisman and Attenborough (1991) show that temperature gradients can exist within a forest and used ray tracing to determine the acoustic effect. But ray tracing can be inaccurate, especially for low frequencies, because 
it does not include surface wave terms which may be important. Measurements in Norway (Hole, 1997) also observed gradients in forest measurements, so this effect may need to be included in propagation models. It is likely that the influence of meteorological conditions will depend on the continuity of the upper canopy.

\section{Additional references not discussed in detail}

There have been many interesting studies of the biological implications of acoustic environment within a forest (Linskens et al. 1976a,b, Martens 1981, Richards and Wiley 1980, Spiesberger and Fristrup 1990, Dabelsteen et al. 1993). Many include detailed measurements, but these papers are not discussed in detail here because they are concerned mainly with short distance, high frequency propagation. One can obtain some indication of the variation to be expected in different forest environments from many detailed measurements (Linskens et al. 1976b).

Some engineering applications, mostly for traffic noise reduction, are also available (Omran et al. 1982, Sneddon et al. 1990, Watts et al. 1999). Finally, a few additional early papers are included in the reference list for completeness (Wiener and Keast 1959, Anon. 1962, Tatge 1965, Dobbins and Kindick 1966).

\section{Other papers}

Two papers are not recommended for use in further studies, and are listed here only for completeness. One (Burns 1979) made measurements on pine boughs, but the resonant frequencies reported for pine needles $2-8 \mathrm{~cm}$ long were extremely low, $20 \mathrm{~Hz}$, compared to all other measurements. This low frequency would imply a wave speed of about $1.5 \mathrm{~m} / \mathrm{s}$ within the needle, which seems incorrect. (Or perhaps the method actually measured a bending or another different type of resonance.) Another paper (Makarewicz 1980) assumed an power function law for attenuation, and then proceeded to calculate multiple reflections and reverberations as is common in seismic reflection processing. But the power law assumption may be incorrect as it disagrees with many published measurements of excess attenuation that do not show a power law relationship. Unfortunately, there was no comparison with any actual data in this reference.

\section{Recommended studies}

Many detailed high-frequency measurements within various forests are available (Linskens et al. 1976b). Detailed physical measurements of the properties of forest soils (Martens et al. 1985a) are also useful. 
Perhaps the best matching of short range measurements $(24 \mathrm{~m})$ to theoretical predictions over a wide frequency band is the study by Price et al. (1988). These authors used the ground effect and scattering only, with a second, lossy term to simulate absorption (see Fig. 2).

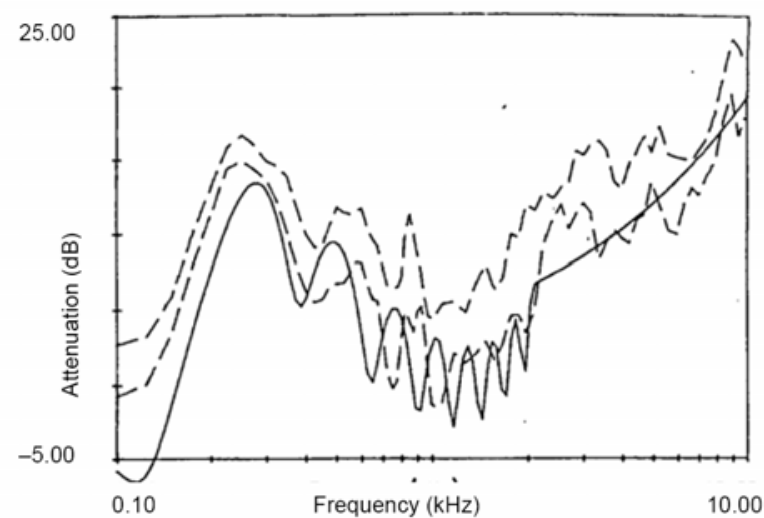

Figure 2. Measured and predicted acoustic attenuation in a forest for a short range experiment $(24 \mathrm{~m})$. Solid line is predicted value, dashed lines are measured values. (After Price et al. 1988.)

An extensive series of measurements using explosives has been conducted in a forested area in Norway (Guice et al. 1998). These data have been only partially analyzed to date. One paper pointed out some of the environmentally induced changes apparent in the blast waveforms (White 1996). Studies have been published discussing the influence of atmospheric conditions on the measurements (Hole 1997, Hole et al. 1997). One study did detect higher attenuation at $63 \mathrm{~Hz}$ within a forest (Hole et al. 1997), but this determination was based on comparison with a modeled prediction that used viscoelastic ground instead of a porous surface. A more straightforward analysis of these waveforms is recommended.

\section{SUMMARY AND RECOMMENDATIONS}

This literature review reveals that the primary effect of the forest on low frequency sound propagation will be from the ground effect, and increased attenuation is expected because the ground is expected to be acoustically "softer" (more porous) than ground in open areas. Scattering from tree trunks and limbs is small, and the absorption from the vegetation itself is neglegible at low frequencies. The 
source and receiver geometry and the frequency will have large effects on the actual amount in any specific situation.

While the causes of sound attenuation, the ground effect, scattering, and absorption, are now well understood, an extensive survey of published work has shown that there is very little information available for low frequency propagation. Additional work is still needed to determine the effect of a forest on artillery training noise or blast noise. Analysis of a unique data set recorded in Norway is recommended, along with additional measurements to determine the effect of forests on low frequency impulse noise.

\section{REFERENCES}

Albert, D.G., and J.A. Orcutt (1990) Acoustic pulse propagation above grassland and snow: Comparison of theoretical and experimental waveforms. Journal of the Acoustical Society of America, 87: 93-100.

Allard, J.F. (1993) Propagation of Sound in Porous Media. Elsevier, London.

Anon. (1962) Acoustic backgrounds., Defense Research Corp., Santa Barbara California.

Attenborough, K. (1992) Ground parameter information for propagation modeling, Journal of the Acoustical Society of America, 92: 418-427.

Aylor, D. (1972a) Noise reduction by vegetation and ground. Journal of the Acoustical Society of America, 51: 197-205.

Aylor, D. (1972b) Sound transmission through vegetation in relation to leaf area density, leaf width, and breadth of canopy. Journal of the Acoustical Society of America, 51: 411-414.

Aylor, D.E. (1981) Comments on foliage as a low-pass filter: Experiments with model forests in an anechoic chamber. Journal of the Acoustical Society of America, 70: 891.

Bullen, R., and F. Fricke (1982) Sound-propagation through vegetation. Journal of Sound and Vibration, 80: 11-23.

Burns, S.H. (1979) The absorption of sound by pine trees. Journal of the Acoustical Society of America, 65: 658-661.

Chien, C.F., and W.W. Soroka (1975) Sound propagation along an impedance plane. Journal of Sound and Vibration, 43: 9-20. 
Dabelsteen, T., O.N. Larsen, and S.B. Pedersen (1993) Habitat-induced degradation of sound signals: quantifying the effects of communication sounds and bird location on blur ratio, excess attenuation, and signal-to-noise ratio in blackbird song. Journal of the Acoustical Society of America, 93: 2206-2220.

Decato, S.N., D.G. Albert, J. F.E. Perron, and D.L. Carbee (2002) Blast noise propagation through forest: Seismic and acoustic signature measurements at the U.S. Army Ammunition Plant, Texarkana, Texas. ERDC-CRREL Contract Report, Hanover, New Hampshire.

DeFrance, J., N. Barriere, and E. Premat (2002) Forest as a meterological screen for traffic noise. In Proceedings of the 9th International Congress on Sound and Vibration.

Dobbins, D.A., and C.M. Kindick (1966) Jungle acoustics: transmission and audibility of sounds in the jungle. Army Tropic Test Center, Fort Clayton Canal Zone.

Don, C.G., and A.J. Cramond (1985) Soil impedance measurements by an acoustic pulse technique. Journal of the Acoustical Society of America, 77: 16011609.

Donato, R.J. (1976) Propagation of a spherical wave near a plane boundary with complex impedance. Journal of the Acoustical Society of America, 60: 34-39.

Embleton, T.F.W. (1996) Tutorial on sound propagation outdoors. Journal of the Acoustical Society of America, 100: 31-48.

Embleton, T.F.W., J.E. Piercy, and G.A. Daigle (1983) Effective flow resistivity of ground surfaces determined by acoustical measurements. Journal of the Acoustical Society of America, 74: 1239-1244.

Eyring, C.F. (1946) Jungle acoustics. Journal of the Acoustical Society of America, 18: 257-270.

Guertin, P.J., and M.J. White (2003) Forest physical sampling strategies for investigating noise mitigation benefits. Journal of the Acoustical Society of America, 114(2, Part 2): 2441-2442.

Guice, R.L., L.R. Hole, A. Jenssen, and G. Kerry (1998) Impulsive noise measurements in a forest during summer and winter conditions, Noise Control Engineering Journal, 46: 185-189.

Heijden, L.A.M.v.d., V. Claessen, and N. Decock (1983) Influence of vegetation on acoustic properties of soils. Oecologia, 56: 226-233. 
Heisler, G.M., S.R. Stebbins, M.P. Denecke, R. Guzman, and M. Swearingen (2000) Bibliography on forest effects on outdoor sound propagation with special emphasis on military noise sources, including effects on people and wildlife. USDA Forest Service, Syracuse, New York, unpublished.

Hole, L.R. (1997) An experimental and theoretical study of propagation of acoustic pulses in a strongly refracting atmosphere. Applied Acoustics, 53: 7794.

Hole, L.R., P. Lunde, and Y.T. Gjessing (1997) Effects of strong sound velocity gradients on propagation of low-frequency impulse sound: comparison of fast field program predictions and experimental data. Journal of the Acoustical Society of America, 102: 1443-1453.

Huisman, W.H.T., and K. Attenborough (1991) Reverberation and attenuation in a pine forest, Journal of the Acoustical Society of America, 90: 2664-2677.

Ingard, K.U. (1951) On the reflection of a spherical wave from an infinite plane. Journal of the Acoustical Society of America, 23: 329-335.

Leschnik, W. (1980) Sound propagation in urban and forest areas. Acustica, 44: $14-22$.

Lindsay, R.B. (1960) Mechanical Radiation. McGraw Hill, New York.

Linskens, H.F., M.J.M. Martens, H.J.G.M. Hendriksen, A.M. Roestenbergsinnige, W.A.J.M. Brouwers, A.L.H.C.v.d. Staak, and A.M.J. StrikJansen (1976a) Acoustic climate of plant communities. Oecologia, 23, 165-177.

Linskens, H.F., M.J.M. Martens, H.J.G.M. Hendriksen, A.M. RoestenbergSinnige, W.A.J.M. Brouwers, A.L.H.C.v.d. Staak, and A.M.J. Strik-Jansen (1976b) The acoustic climate of plant communities. Oecologia, 23: 165-177.

Makarewicz, R. (1980) Phenomenology of sound-propagation through a green belt. Journal of Sound and Vibration, 72: 481-489.

Martens, M.J.M. (1980) Foliage as a low-pass filter: Experiments with model forests in an anechoic chamber. Journal of the Acoustical Society of America, 67: $66-72$.

Martens, M.J.M. (1981) Noise abatement in plant monocultures and plant communities. Applied Acoustics, 14: 167-189.

Martens, M.J.M., and A. Michelsen (1981) Absorption of acoustic energy by plant-leaves. Journal of the Acoustical Society of America, 69: 303-306. 
Martens, M.J.M., and W.H.T. Huisman (1986) Ecosystem acoustics research $\backslash$. In Sound Propagation in Forested Areas and Shelterbelts, Nijmegen, The Netherlands, pp. 13-23.

Martens, M.J.M., J.A.M.v. Huet, and H.F. Linskens (1982) Laser interferometer scanning of plant-leaves in sound fields. In Proceedings of the Koninklijke Nederlandse Akademie Van Wetenschappen Series C-Biological and Mmedical Sciences, 85: 287-292.

Martens, M.J.M., L.A.M.V.d. Heijden, H.H.J. Walthaus, and R.W.J.J.M. van (1985a) Classification of soils based on acoustic-impedance, air-flow resistivity, and other physical soil parameters. Journal of the Acoustical Society of America, 78: 970-980.

Martens, M.J.M., P.P.J. Severens, H.A.W.M.v. Wissen, and L.A.M.v.d. Heijde (1985b) Acoustic reflection characteristics of deciduous plant-leaves. Environmental and Experimental Botany, 25: 285-292.

Morse, P.M., and K.U. Ingard (1968) Theoretical Acoustics. Princeton University Press, Princeton,

Nannariello, J., and F. Fricke (1999) The prediction of reverberation time using neural network analysis. Applied Acoustics, 58: 305-325.

Omran, T.A., K.A. Elshorbagy, and A.B. El-Sayed (1982) Attenuation of noise by windbreaks. Applied Acoustics, 15: 389-395.

Pao, S.P., and L.B. Evans (1971) Sound attenuation over simulated ground cover. Journal of the Acoustical Society of America, 49: 1069-1075.

Piercy, J.E., T.F.W. Embleton, and L.C. Sutherland (1977) Review of noise propagation in the atmosphere, Journal of the Acoustical Society of America, 61: 1403-1418.

Price, M.A., K. Attenborough, and N.W. Heap (1988) Sound attenuation through trees: Measurements and models. Journal of the Acoustical Society of America, 84: 1836-1844.

Rayleigh, J.W.S. (1945) The Theory of Sound. Dover Publications, New York.

Reethof, G., L.D. Frank, and O.H. McDaniel (1976) Absorption of sound by treebark. Northeastern Forest Experiment Station, Broomall, Pennsylvania.

Richards, D.G., and R.H. Wiley (1980) Reverberations and amplitude fluctations in the propagation of sound in a forest-implications for animal communication. American Naturalist, 115: 381-399. 
Ringheim, M. (1986) Attenuation of sound through vegetation: Some results from a literature survey. In Sound Propagation in Forested Areas and Shelterbelts, Nijmegen, The Netherlands, pp. 135-152.

Rudnick, I. (1947) Propagation of an acoustic wave along a boundary. Journal of the Acoustical Society of America, 19: 348-356.

Sakai, H., S. Sato, and Y. Ando (1998) Orthogonal acoustical factors of sound fields in a forest compared with those in a concert hall. Journal of the Acoustical Society of America, 104: 1491-1497.

Sakai, H., S. Shibata, and Y. Ando (2001) Orthogonal acoustical factors of a sound field in a bamboo forest. Journal of the Acoustical Society of America, 109: 2824-2830.

Sneddon, M., S. Fidell, L. Siluati, K.S. Pearsons, and K.H. Robin (1990) Predicting sound levels from wind speed in a coniferous forest. Journal of the Acoustical Society of America, 88: S74 (abstract).

Spiesberger, J.L., and K.M. Fristrup (1990) Passive localization of calling animals and sensing of their acoustic environment using acoustic tomography. American Naturalist, 135: 107-153.

Storeheier, S.A., T.E. Vigran, and A. Lundeby (1995) Blast propagation through forest: Ground characterization. SINTEF DELAB Acoustics Research Center, Trondheim, pp. 24STF40-F95013.

Sutherland, L.C., and G.A. Daigle (1997) Atmospheric sound propagation. In Encyclopedia of Acoustics (M.J. Crocker, Ed.). John Wiley \& Sons, Inc., New York, pp. 341-365.

Swearingen, M., D. Swanson, and K. Eeichard (1998) Survey of research on sound propagation in forests. In Eighth International Symposium on Long-Range Sound Propagation, University Park, Pennsylvania, pp. 131-138.

Swearingen, M.E. (2003) An analytic model for acoustic scattering from an impedance cylinder placed normal to an impedance plane, Ph.D. Dissertation. Pennsylvania State University, University Park.

Swearingen, M.E., and M.J. White (in press) Sound propagation through a forest: a predictive model. Proceedings of the 11th Symposium on Long Range Sound Propagation, 2004.

Talaske, R.H. (1980) The acoustic impedance of a layered forest floor (quoted in van der Heijden et al. 1983). Noise Control Laboratory, Pennsylvania State University, University Park. 
Tang, S.H., P.P. Ong, and H.S. Woon (1986) Monte-carlo simulation of soundpropagation through leafy foliage using experimentally obtained leaf resonance parameters. Journal of the Acoustical Society of America, 80: 1740-1744.

Tatge, R.B. (1965) Forest sound spectrum analysis., General Electric Co., Advanced Technology Labs, Schenectady, New York, pp. 241.

Tunnick, A.( 2003) Calculating the micrometeorological influences on the speed of sound through the atmosphere in forests. Journal of the Acoustical Society of America, 114: 1796-1806.

Umnova, O., K. Attenborough, and A. Cummings (2001) Nonlinear behavior of poroelastic materials. Journal of the Acoustical Society of America, 109: 2453 (abstract).

Van Renterghem, T. (2002) Improving noise barrier performance in wind using a row of trees: A field experiment. In Proceedings of the 9th International Congress on Sound and Vibration.

Watanabe, T., and S. Yamada (1996) Sound attenuation through absorption by vegetation, Journal of the Acoustical Society of Japan, 17: 175-182.

Watts, G., L. Chinn, and N. Godfrey (1999) The effects of vegetation on the perception of traffic noise, Applied Acoustics, 56: 39-56.

West, M. (in press) Range dependent predictions using parabolic equation models. In Proceedings of the 11th Symposium on Long Range Sound Propagation, 2004.

White, M.J. (1996) Forest soundings: Interpretations of pressure waveforms of explosions at distances up to $20 \mathrm{~km}$. In InterNoise 96, pp. 555-560.

White, M.J., L.L. Pater, R.J. Lee, and J. G.W. Swenson (2003) Attenuation of blast sound by a mixed stand of pine and hardwood. Journal of the Acoustical Society of America, 114(4, Part 2): 2441.

Wiener, F.M., and D.N. Keast (1959) Experimental study of the propagation of sound over ground. Journal of the Acoustical Society of America, 31: 724-733. 


\section{APPENDIX A: RECENT WORK}

The bulk of this report was written in 2001 as the Blast Noise Propagation Through Forest project was starting. Since that time, experimental measurements have been conducted at the Lone Star Army Ammunition Plant in Texarkana, Texas, as recommended in this review. In addition, a few other reports have recently been published. This Appendix briefly discusses that new work.

Two papers on forest effects were presented at a conference in 2002. Defrance et al. (2002) calculated the effect of a strip of forest 100 m wide on road noise, using a parabolic equation method including multiple scattering from hard cylinders to represent the forest. The source frequency was not stated but the results were all A-weighted, so this was a high frequency study that will not be relevant to Army noise problems. The authors found that sound could be enhanced at some distances under certain meteorological conditions, although their measurements did not show this effect. They concluded that trees were only generally effective in locations close to the end of the forest, and that the maximum sound reduction in most situations was 1 to $3 \mathrm{~dB}(\mathrm{~A})$. Van Renterghem (2002) studied the effect of nearby trees on wind screen performance on traffic noise, and found that the trees, by modifying the local wind parameters, could improve windscreen performance by reducing refraction effects that tend to enhance sound levels. This was also an A-weighted study not directly applicable to Army noise sources.

Swearingen (2003) developed an analytical model of a scattering from a single vertical cylinder, including the ground effect, and found good agreement with measurements below $1500 \mathrm{~Hz}$.

Tunick (2003) calculated sound transmission loss through forests at frequencies of 100, 200,300, and $400 \mathrm{~Hz}$ and ranges up to $500 \mathrm{~m}$. This study includes realistic meteorological profiles within the forest based on energy balance models of heat and radiation transfer. (The general agreement with measured meteorological profiles is good, but the steep gradients predicted by the model still need to be confirmed by measurements, and these will be important for acoustic predictions.) Within the forest, sound pressure levels are always lower than for open grass-covered areas, but the forest values can increase or decrease compared to a homogeneous atmospheric profile depending on the actual meteorological profile.

West (in press) presented an approximate meteorological profile for forests that displaced the expected profile in an open area to begin above the canopy, with a relatively constant meteorological profile in the forest itself. The profile 
above the forest was compressed in height so as to eventually match the original profile in an open area. This compression would tend to enhance refraction effects for acoustic waves traveling above the canopy. Both Tunick's and West's acoustic predictions need to be confirmed with acoustic measurements.

Currently, a number of publications are in preparation resulting from the ERDC study of blast noise propagation through forests. As mentioned above, measurements were conducted using C-4 explosions and propagation distances from 30 to $500 \mathrm{~m}$ through a forested area. White et al. (2003) have presented preliminary results of these measurements, and an ERDC report on some of the measurements is in preparation (Decato et al. 2002). A method of characterizing the forest has also been developed (Guertin and White 2003). Swearingen and White (in press) have presented a preliminary model of propagation through the forest that includes multiple scattering in a way similar to Price et al. (1988) and Van Renterghem (2002). Additional publications on this experimental work are in preparation.

Finally, mention is made of an extensive unpublished bibliography . This bibliography lists many reports and includes a summary of each item prepared by the compilers (Heisler et al. 2000, unpublished). 


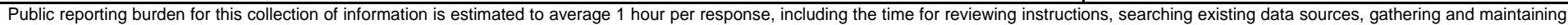

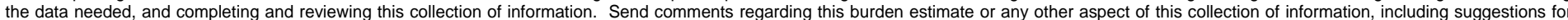

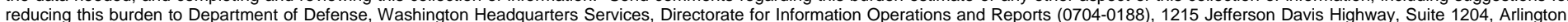

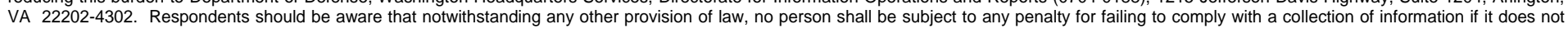
display a currently valid OMB control number. PLEASE DO NOT RETURN YOUR FORM TO THE ABOVE ADDRESS.
1. REPORT DATE $(D D-M M-Y Y Y Y)$
2. REPORT TYPE
October 2004
3. DATES COVERED (From - To)

4. TITLE AND SUBTITLE

Past research on sound propagation through forests

5a. CONTRACT NUMBER

b. GRANT NUMBER

5c. PROGRAM ELEMENT NUMBER

6. AUTHOR(S)

Donald G. Albert

5d. PROJECT NUMBER

5e. TASK NUMBER

5f. WORK UNIT NUMBER

7. PERFORMING ORGANIZATION NAME(S) AND ADDRESS(ES)

8. PERFORMING ORGANIZATION REPORT NUMBER

Cold Regions Research and Engineering Laboratory

72 Lyme Road

ERDC/CRREL TR-04-18

Hanover, NH 03755-1290

9. SPONSORING I MONITORING AGENCY NAME(S) AND ADDRESS(ES)

10. SPONSOR/MONITOR'S ACRONYM(S)

11. SPONSOR/MONITOR'S REPORT NUMBER(S)

\section{DISTRIBUTION / AVAILABILITY STATEMENT}

Approved for public release; distribution is unlimited

\section{SUPPLEMENTARY NOTES}

\section{ABSTRACT}

This report reviews past scientific research to determine whether forests have any noise reduction effects for blast noise from artillery training or explosions. Unfortunately, there has been very little relevant work that would contribute to answering this question. For military noise sources, the main frequencies of interest are below $100 \mathrm{~Hz}$. Most of the past investigations have been done at high frequencies using low-amplitude continuous wave noise sources rather than highamplitude impulsive sources. For these reasons, additional measurements will be needed to determine the effect of forests on artillery and blast noise.

\section{SUBJECT TERMS}

Acoustics

Blast noise

16. SECURITY CLASSIFICATION OF:

a. REPORT

Unclassified b. ABSTRACT

Unclassified
Forest effects

Sound propagation

Trees

c. THIS PAGE

Unclassified
17. LIMITATION OF ABSTRACT

Unclassified
18. NUMBER OF PAGES

23 19a. NAME OF RESPONSIBLE PERSON

19b. TELEPHONE NUMBER (include area code) 
